\title{
The Psychoanalytic Interpretation of the Organizational Environment as a Management Tool for Sustainable Development
}

\author{
Elena Khripko ${ }^{1, *}$ \\ ${ }^{1}$ Moscow State University of Civil Engineering, 129337 Yaroslavskoe sh. 26, Moscow, Russia
}

\begin{abstract}
The article exposes contemporary materials and structures for sustainable development of organizational environment. Psychoanalytic modeling of organizational behavior makes it possible to identify out reflection, unconscious tendencies in individual, group and corporate behavior. This enables to significantly increase the effectiveness of measures for personnel management. Organizational Environment Researches base on psychoanalytic theory of object relations.
\end{abstract}

\section{Introduction}

Sustainable development of organization depends on the quality of application of managing function. And this issue in its turn depends on the functioning level and status of organizational environment.

The present research offers a new level of understanding of problematics of management decisions in organizations related to training, development, selection, motivation, as well as issues of staff efficiency as a whole. At present, systematic character have the problems which in general can be summarized as follows: the results of organizational activities in the field of human resources management aimed at increasing of activity efficiency do not match the initial requests.

Training and development staff programs, corresponded to organization standards, and performed with high quality, do not reach the target level of development of competencies.

In turn, the results of personnel evaluation may also be in conflict with the results of training activities, do not correlate with real image of organizational dynamics, do not provide complete information to answer the most important management problems. The revision of educational programs, organizational changes and personnel changes often do not achieve significant results. Without answering remains the question about what educational programs will bring the quality of organizational collaboration at the appropriate level?

Psychoanalytic approach allows us to put forward the hypothesis that there are hidden processes which affect the organizational environment, causing these contradictions, despite the taken measures. But the failures of personnel policy are not random at all, but

\footnotetext{
* Corresponding author: geleda@ya.ru
} 
are due to underlying causes, and there is a cause-and-effect relation between the manifestations of organizational culture and individual psychological reactions of employees [1-29].

\section{The psychoanalytic interpretation of the organizational environment}

Consideration of organizational processes reveals another contradiction: personnel evaluation provides some information on the development of competencies, but on practice of the organizational behavior it is translated its another level. Often there is a situation where in spite of all taken measures appear a stable for a given organizational environment patterns of destructive behavior. The paradox of destructive stereotypes is that they are translated by employees that are different by their psychological characteristics. In such cases, any measures will be ineffective unless they are based on the idea of hidden content of organizational dynamics and do not include the tasks of identifying of the unconscious nature of destructive reactions.

Let me illustrate as noted above through the example of personnel evaluation. The results of personnel evaluation have revealed a certain level of necessary skills development, but in reality the same employees don't show the desired level of competence, on the contrary, their organizational behavior is deformed by unpredictable patterns of behavior and destructive influence on the surrounding activities. [2]

These facts go to prove that important aspects havent't been taken into consideration of personnel evaluation and were not displayed in its results. The lack of problems understanding of similar cases is that competency is the basis of a rational level among employees, its rational organizational behavior is modelled without notice of distortions caused by the unconscious tendencies.

The psychoanalytic interpretation of unconscious tendencies in the organization provides an opportunity to improve the quality of management decision making. Detection and interpretation of these non-reflexive stereotypes of organizational behavior significantly allows to improve the corporate governance as a whole.

The psychoanalytic research of social and group phenomena was proposed by Freud. The development of psychoanalytic theory and practice was as a basis of the modern psychoanalysis, where some fields of research were organizational processes. The psychoanalytic researches in organizational context are the most effective to me that are based on object relations theory [3, 4].

The psychoanalytic research of social and group phenomena is provided by means of met psychological models, reconstruction of the latent content and quality of object relations. The structure modeling from the perspective of the psychoanalytic approach presents the organizational content from the perspective of structures like the ego, the superego and the id. [5] The interaction between individuals and groups creates a specific range of defense mechanisms for all organization, and formal and informal organizational relationships get a certain quality. Analyzing communication skills, it becomes possible to create such a model where the organizational behavior is described as a result of the dynamic interaction between structures like the ego, the superego and the id.

Functioning of the organizational ego is simulated on the basis of information about the nature of communication, translation mechanisms of information, the interaction with the environment and the nature in organizational relationships.

Functioning of the organizational superego shows the organizational structure and the way it is related to the communication system. The nature of the superego functioning is found in the study of the incentive system and the system of penalties, methods and forms of control of assignments at different levels of management. 
The id energy is manifested in traditions, communication affects. Conflict situations are the most informative in this context. Applying the structure modeling in the organizational context makes it possible to predict what organizational affects will be mobilized, what defense mechanisms will be involved, what conflict trends will be engaged into a given situation, and the most important thing is what hidden tendencies cause the distortion in the organizational context and what ways it is advisable to reduce their impact.

The system psychoanalytic study of organizational communications allows for the conclusion about the quality of object relations in the organizational context. Understanding the quality of object relations allows to predict the consequences of certain organizational measures to a high precision, to choose the optimal paths of implementing organizational changes.

The psychoanalytic position in the organizational context can attribute a symbiotic, separational or triad character of object relations. This view involves a range of assumptions. The reference of the organizational context to one of these three types is carried out by the fact what quality of object relations in organizational communications and what defense mechanisms are mainly interpreted.

Symbiotic cultures are characterized by the lack of borders differentiation in the the employee-organization system. The organizational context is marked by a number of defense mechanisms. First of all, it concerns imagination. At multiple communication levels you can view the prevalence of imagination (mostly about the future) than the interpretation of the organizational reality. In addition to the above there is a total control of information and activities. The discussion of innovations is accompanied by a primitive idealization and devaluation. Most of organizational situations are resolved through catharsis - rapid untested and unprepared appointments and dismissals, organizational reorganizations and other such actions. They show the desire to obtain instant results by radical and rapid problem resolution.

In the separation cultures you can trace diffuse boundaries in the employee-organization system, object relations are manifested with the lack of integration, the diffusion of responsibilities. It is clearly traced the perception of internal and external objects as absolutely "good" or absolutely "bad". Among the defense mechanisms the extrajection brings to the forefront. This defense mechanism is clearly appeared within the interaction with different units, whereby the organizational behavior of employees is characterized by instability and unpredictability.

The organizational context has the triode quality of object relations and shows mature defense mechanisms, and the organizational culture has an integrated identity. Managerial decisions are mainly thought out and widely discussed. The organizational conflicts of interests get a complex nature involving many participants, they can exist for a long time in a latent form.

In this article I want to fix on the most striking flashes, present a sort of sketch of object relations, as a detailed psychoanalytic description of the typology of corporate cultures requires the consideration of a considerable amount of facts that will be implemented in future publications on the subject.

In practice the organizational consulting of psychoanalytic research is carried out according to the request that the manager makes an inquiry.In some cases, the inquiry covers the organizational dynamics as a whole, and there is enough information about the psychoanalytic modeling in the organizational context.

In other inquiries the problem is specified, and the focus of the study is limited for this problem ofinformation content. The research should be carried out exclusively in the request scope, because the process of identification and interpretation of the hidden trends inevitably meets resistance from the organizational context, even in cases when the situation is complex and requires instant effective actions. At the moment the 
organizational context with a particular quality of object relations has a definite transfer of resources of certain hidden trends on a conscious level. The existence of an inquiry to change the organizational context does not indicate the existing availability to the realities of these changes. The realization of latent tendencies, the interpretation of a cause-andeffect relationship of different organizational phenomena is one of the most important working phases, but more difficult job is to change the current situation, its testing, the consideration and the implementation into the organizational context.

\section{Conclusion}

In practice of organizational consulting stick to the following steps:

- the discussion of the original inquiry, the detection of the scope of activities, the formulation of marking criteria results;

- the collection and analysis of information under the frame of the inquiry;

- the psychoanalytic modeling of an organizational context on the basis of provided information and the interpretation of the latent content;

- the discussion of options for possible changes;

- the evaluation of changes and the study on resistance in the organizational context;

- the implementation of coherent changes in the form of personnel decisions, development programs, and etc.;

- the feedback for the direction of this inquiry.

When applying the psychoanalytic approach, we can achieve the reduction of risks in management decision making, staff recruitment and key appointments. The detection of previously hidden cause-and-effect relationships makes it possible to clarify the worthwhileness of organizational effects and exercise an option of these effects to a qualitatively new level.

\section{References}

1. E.V. Romanova, Izvestiya VGPU, 89, 115-123 (2014)

2. N.G. Miloradova, A.D. Ishkov, Psychology of management activity: changing approach (MGSU, Moscow, 2014)

3. O. Kernberg, Ideology, Conflict, and Leadership in Groups and Organizations (Nezavisimaya firma "Class", Moscow, 2015)

4. N. McWilliams, Psychoanalytic Diagnosis: Understanding Personality Structure in the Clinic Process (Nezavisimaya firma "Class", Moscow, 2006)

5. E. Berne, Leadershipand group. Structure and Dynamics of Organizations and Groups (Izdatel'stvo «E», Moscow, 2016)

6. J. Ćetković, S. Rutešić, M. Zarković, M. Knežević, , N.Vatin, Procedia Engineering, 117 (1), 780-790 (2015)

7. S. Rutešić, J. Ćetković, M. Žarcković, M. Knežević, N. Vatin, Procedia Engineering, 117 (1), 905-915 (2015)

8. S. Rutešić, J. Ćetković, M. Knežević, M. Žarcković, N. Vatin, Procedia Engineering, 117(1), 642-650 (2015)

9. M. Jevrić, M. Knežević, J. Kalezić, N. Kopitović-Vuković, I. Ćipranić, Tehnicki Vjesnik, 21(4), 873-879 (2014)

10. N. Pavličić, M. Perazić, D. Durić-Jocić, M. Knežević, Journal of Applied Engineering Science, 12(1), 11-18 (2014)

11. J. Ćetković, M. Knežević, M. Žarković, V. Murgul, N. Vatin, Applied Mechanics and Materials, 638-640, 2465-2470 (2014) 
12. M. Lazarevska, M. Milanović, M. Knežević, M. Cvetkovska, A. T. Gavriloska, T. Samadzioska, Journal of Applied Engineering Science, 12(1), 63-68 (2014)

13. J. Cetkovic, M. Knezevic, I. Vujovic, J. Cerovic, Technics Technologies Education Management, 7(4), 1646-1654 (2012)

14. M. Knežević, Journal of Applied Engineering Science, 10(1), (2012)

15. J. Cetkovic, S. Rutesic, T. Hanak, M. Knezevic, B. Melovic, Technics Technologies Education Management, 7(1), 285-293 (2012)

16. B. Kovačič, R. Kamnik, A. Štrukelj, Promet - Traffic - Traffico, 22(1), 15-22 (2010)

17. N. Gubeljak, J. Predan, D. Kozak, J. Tuma, B. Kovačič, P. Konjatić, J. Sertić, Strojarstvo, 51(4), 263-271 (2009)

18. B. Kovačič, R. Kamnik, M. Premrov, N. Gubeljak, J. Predan, Z. Tišma, Strojniski Vestnik/Journal of Mechanical Engineering, 54(5), 364-371 (2008)

19. B. Kovačič, R. Kamnik, International Journal for Engineering Modelling, 20(1-4), 7784 (2007).

20. N. Lipovac, A.M., Jandriček, Prostor, 19(2), 443-455 (2011)

21. V.V Okrepilov, M.V. Leonidovich, Asian Social Science, 11(7), 312-325 (2015)

22. V.V Okrepilov, V.L. Makarov, A.R. Bakhtizin, S.N Kuzmina, Economy of Region, 2, 301-313 (2015)

23. V.L. Kvint, V.V Okrepilov, Herald of the Russian Academy of Sciences, 84(3), 188$200(2014)$

24. V.V Okrepilov, V.N. Krutikov, G.I. El'kin, Measurement Techniques, 57(2),109-116 (2014)

25. V.V Okrepilov, A.Yu. Smirnov, Measurement Techniques, 56(1), 54-60 (2013)

26. V.V Okrepilov, Studies on Russian Economic Development, 24(1), 35-42 (2013)

27. V.V Okrepilov, Standarty i Kachestvo, 10, 52-55 (2005)

28. V.V Okrepilov, G. Ivanova, Standarty i Kachestvo, 12, $62-68$ (2004)

29. V.V Okrepilov, Standarty i Kachestvo, 3, 94-96 (2003) 